OPEN ACCESS

Edited by:

Jiang Bian,

China University of Petroleum (East

China), China

Reviewed by:

Hu Guo,

China University of Petroleum, Beijing,

China

Yang Xiao,

Xi'an University of Science and

Technology, China

${ }^{*}$ Correspondence:

Anzhao Ji

jianzhao_831024@163.com

Specialty section:

This article was submitted to Advanced Clean Fuel Technologies,

a section of the journal

Frontiers in Energy Research

Received: 06 December 2021

Accepted: 14 January 2022

Published: 25 February 2022

Citation:

Ji A, Chen Z, Wang Y, Zhang G, Mao Z and Chen $F$ (2022) A Semi-Analytical

Mathematical Model for Off-Center

Fractured Vertical Wells With

Asymmetrical Fractures in Columnar

Coalbed Methane.

Front. Energy Res. 10:829914.

doi: 10.3389/fenrg.2022.829914

\section{A Semi-Analytical Mathematical Model for Off-Center Fractured Vertical Wells With Asymmetrical Fractures in Columnar Coalbed Methane}

\author{
Anzhao $\mathrm{Ji}^{1 *}$, Zhanjun Chen ${ }^{1}$, Yufeng Wang ${ }^{1}$, Guangsheng Zhang ${ }^{1}$, Zhenglin $\mathrm{Mao}^{2}$ and \\ Fenjun Chen $^{3}$
}

${ }^{1}$ School of Energy Engineering, Longdong University, Qingyang, China, ${ }^{2}$ Research Institute of Exploration Development, PetroChina Southwest Oil \& Gasfield Company, Chengdu, China, ${ }^{3}$ Research Institute of Exploration Development, PetroChina Qinghai Oil Field Company, Dunhuang, China

Coalbed methane (CBM) is one of the important unconventional oil and gas resources. Since the permeability of the CBM reservoir is very low, CBM is usually developed by hydraulic fracturing technology to enhance gas productivity. In fact, most of the wells are not at the center of the columnar CBM reservoirs, which leads to different wellbore pressure responses. It is meaningful to analyze the wellbore pressure response of the offcenter fractured vertical wells with asymmetrical fracture. The adsorption-desorption, fracture asymmetry are considered and a semi-analytical mathematical model is established. The pressure wellbore solution of the Laplace domain can be obtained by Laplace transformation, model coupling, and Gauss elimination. Then, the Stehfest numerical inversion is employed to obtain the pressure solution and rate distribution in the real-time domain. This semi-analytical solution is verified; the results show that the wellbore pressure includes six flow regimes, which include bilinear flow, linear flow, elliptic flow, radial flow, arc boundary reflection, and boundary dominated flow regime. The influence of fracture angle, dimensionless conductivity, and off-center distance on wellbore pressure and rate distribution are discussed in detail.

Keywords: hydraulically fractured well, coalbed methane, off-center well, asymmetrical fracture, pressure transient response

\section{INTRODUCTION}

Owing to the complicated seepage mechanism of CBM, CBM is classified as an unconventional natural gas resource. As one of the vital unconventional resources, development of CBM has been a global concern. The gas is stored in coal beds and there are many natural fractures in CBM reservoirs, which provide the seepage channels for gas flow (Zuber and Kuuskraa, 1990; Aminian and Ameri, 2009). Since the permeability of the CBM reservoir is very low, hydraulic fracturing measures are employed to enhance the production of coalbed methane. The complexity of formation conditions leads to the hydraulic fracture being asymmetric to the wellbore. Pressure transient analysis is an important approach for reservoir evaluation and production performance prediction. Therefore, we can diagnose whether the well is in the 
center of the reservoir and calculate the distance from the well to the center of the reservoir by pressure transient analysis.

The main component of CBM is methane. CBM reservoirs consist of matrix and natural fractures systems, and there are many small-diameter pores in coal matrix particles. The transport of CBM includes the desorptionand diffusion of CBM in smalldiameter pores, and flow through a network of natural fractures (Liu et al., 2020; Nie et al., 2012; Pillalamarry et al., 2011; H.; Wang et al., 2021). However, the above-cited research mainly focuses on micro seepage. There is no research on the unsteady seepage of wellbore pressure in CBM, which cannot evaluate pressure wave propagation directly.

Hydraulic fracturing technology is often used to enhance the production of CBM. Many scholars have carried out research on the unsteady flow theory of vertically fractured wells (Cinco-Ley and Meng, 1988; Huang et al., 2015; Wang and Wang, 2014; L.; Wang et al., 2012). Cinco-Ley and Meng, (1988) presented the approach to couple the hydraulic fracture model and surface source solution firstly, then Huang et al. (2015) and presented an analytical model of a vertically fractured well to stimulate the relationship between wellbore pressure and production time. However, their works assumed that the fractures are symmetrical around the wellbore, which is not consistent with the reality.

In practice, the complexity of the conditions of the reservoir leads to hydraulic fracture being asymmetric around the wellbore. Some scholars simulated wellbore pressure transient response via numerical simulation (Bennett et al., 1983; Berumen et al., 2000; Crawford and Landrum, 1955; Narasimhan and Palen, 1979) and semi-analytical approach (Rodriguez et al., 1992; Tiab et al., 2010; Wang et al., 2019; Wang et al., 2013; Wang and Wang, 2014; Wang and Xue, 2018; Zhao et al., 2019). Crawford and Landrum (1955) firstly introduced a fracture asymmetry mathematical model but meaningful conclusions could not be drawn. Bennett et al. (1983) discussed the influence of the asymmetrical fracture on the rate decline curve by the numerical simulation methods. Wellbore pressure response curve under the condition of constant rate is analyzed by employing the numerical simulation methods (Berumen et al., 2000; Narasimhan and Palen, 1979). Their results showed that fracture asymmetry has an obvious influence on the wellbore pressure curve during the bilinear flow regime. Since the numerical solution is low efficiency and accuracy, some scholars introduced the analytical and semi-analytical approaches to obtain the wellbore pressure. Rodriguez et al. (1992) and Tiab et al. (2010) introduced the analytical method of vertical well with asymmetric hydraulic fracture firstly, but their model only gives the pressure solution of the hydraulic fracture. In order to couple the hydraulic fracture model and reservoirs model, (Wang et al., 2013, 2014, 2018, 2019) introduced the fracture Green's function and coupled the hydraulic fracture and reservoirs model. Finally, a wellbore pressure curve during the whole flow regime is obtained. Zhao et al. (2019) analyzed the wellbore pressure curve of fractured wells with asymmetric fractures by combining the boundary element method and source function. Although they had carried out a lot of research on the wellbore pressure response of fractured wells with asymmetric fractures, their models assumed that vertical well is the center of the CBM reservoirs.
Assuming the well is the center of the reservoir is an ideal model. Based on an "equivalent well block radius," Peaceman (1990) presented the simulation method of an off-center well by reservoir numerical simulation. Rosa et al. (1996) presented the off-center vertical well analytical model of radial composite reservoirs with an internal circular discontinuity. However, their research object is vertical wells. Deng et al. (2017) presented the semi-analytical model of the off-center vertical fractured well with a bi-wing symmetrical fracture in a multi-region heterogeneous reservoir to analyze the wellbore pressure behavior. Zhao et al. (2017) presented the semi-analytical solution of the off-center vertical fractured well with bi-wing symmetrical fracture by combining the boundary element method and source function. Although they were given the semi-analytical solution of hydraulic fractured well, their model assumed that the fracture is symmetrical about the wellbore.

Based on the above literature and research, there is no research about off-center fractured vertical wells with an asymmetrical fracture in columnar coalbed methane. In fact, for columnar gas reservoirs with circlar closed boundaries, wellbore is not often the center of circle closed reservoirs and the bi-wing of hydraulic fracture is unequal length because of the influence of reservoir anisotropy. Therefore, the major work of this paper can be summarized as follows.

- An efficient semi-analytical mathematical model of offcenter fractured well with an asymmetrical fracture is established and solved.

- Wellbore pressure characteristics curve is discussed and verified with numerical solution.

- The influence of key parameters on wellbore pressure and rate distribution curve is discussed.

Firstly, some assumptions are made and a physical model schematic diagram is shown. Secondly, the governing equations of the 2D CBM reservoirs model and 1D hydraulic fracture are established and solved. Thirdly, discretizing fracture as many small segments, and pressure drop superposition is used to obtain the relationship between wellbore pressure and time. Finally, the influence of some parameters on wellbore pressure and rate distribution curve is analyzed.

\section{PHYSICS MODEL AND BASIC ASSUMPTION}

The CBM reservoirs are composed of matrix and natural fracture systems and natural fracture is the main seepage channel to connect with hydraulic fracture. The wellbore is not the center of the CBM reservoir, and hydraulic fracture is asymmetric towards the wellbore (Figure 1). Desorption and diffusion in the matrix are considered. Some basic assumptions are given as follows:

- The gas well product by constant rate $q_{\mathrm{sc}}$.

- The distance from the wellbore to the gas reservoir center is $r_{\mathrm{o}}$.

- There is an angle, $\theta_{\mathrm{F}}$, between fracture and horizontal direction. 


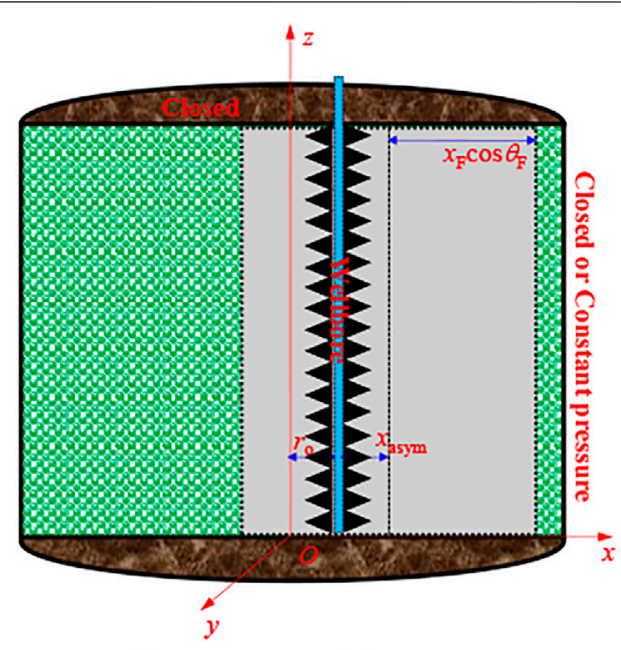

Three dimensional diagram

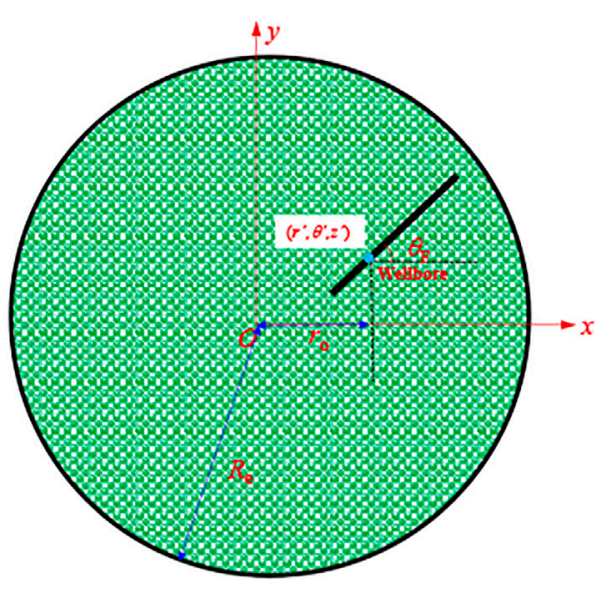

Two dimensional diagram

FIGURE 1 | Schematic diagram of off-centered fractured well with asymmetric fracture.

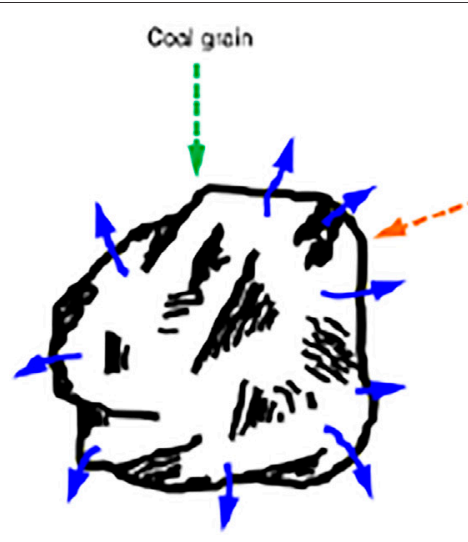

Descrption from a cod frane

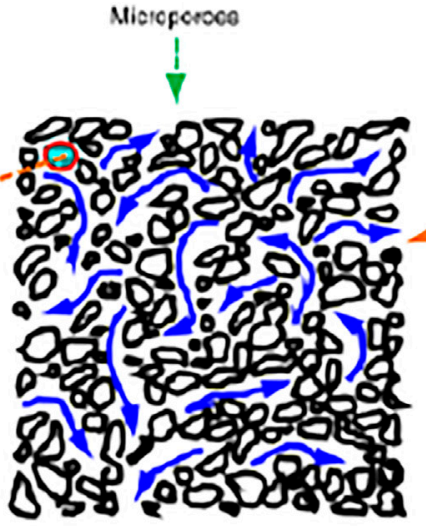

flow in the sold cod matix
Mooreporece
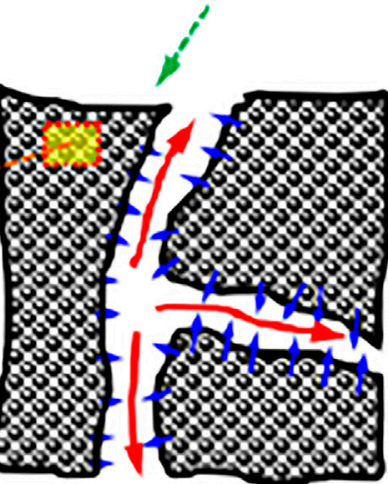

Flow in the fracture netincok

Dfueion in mikropo:es

Dorey flon in fraturee

FIGURE 2 | Schematic diagram of microflow mechanism of coalbed methane (Zhao et al., 2016).

- The two wings of fracture are not equal and the distance from the wellbore to the hydraulic fracture center is $x_{\mathrm{asym}}$.

- The gas flow obeys isothermal Darcy seepage in hydraulic fracture and reservoirs.

- The desorption of adsorbed gas in the coal matrix can be described by Langmuir's isothermal adsorption (Figure 2).

- The outer boundary of the reservoir is a circle closed.

\section{MATHEMATICAL MODEL AND SOLUTION Off-Center Linear Source Function}

Langmuir's isothermal adsorption equation is (Langmuir, 1917; Chen et al., 2016; Zhao et al., 2016; Xu et al., 2020).

$$
V=V_{\mathrm{L}} \frac{p}{p_{\mathrm{L}}+p}
$$

Where: $V_{L}$ is Langmuir volume, $\mathrm{sm}^{3} / \mathrm{m}^{3} ; p_{L}$ is Langmuir pressure, $\mathrm{Pa} ; \mathrm{p}$ is Reservoirs pressure, $\mathrm{Pa} ; \mathrm{V}$ is Shale gas adsorption volume, $\mathrm{sm}^{3} / \mathrm{m}^{3}$.

In order to find the linear governing equation, pseudopressure is defined as:

$$
\psi=2 \int_{p_{0}}^{p} \frac{p}{\mu Z} d p
$$

Where: $\mu$ is CBM viscosity, cp.; $Z$ is gas deviation factor, dimensionless; $\psi$ is pseudo-pressure, $\mathrm{Pa} / \mathrm{s}$. 
TABLE 1 | dimensionless variable definition.

Dimensionless pseudo-pressure

Dimensionless radial distance

Dimensionless time

Storativity ratio

Interporosity coefficient of transient state crossflow

Interporosity coefficient of pseudo-state state crossflow

$$
\begin{aligned}
& \psi_{\mathrm{fD}}=\frac{\pi k_{\mathrm{f}} h T_{s c}}{p_{s c} T q_{s c}}\left(\psi_{\mathrm{e}}-\psi_{\mathrm{f}}\right) \\
& r_{D}=\frac{r}{L_{\mathrm{ref}}} \\
& t_{D}=\frac{k_{\mathrm{f}}}{\left(\phi_{\mathrm{f}} C_{\mathrm{tf}}+\phi_{\mathrm{m}} C_{\mathrm{tm}}\right) \mu L_{\mathrm{ref}}^{2}} t \\
& \omega=\frac{\phi_{\mathrm{f}} C_{\mathrm{tf}}}{\phi_{\mathrm{f}} C_{\mathrm{tt}}+\phi_{\mathrm{m}} C_{\mathrm{tm}}} \\
& \lambda=\alpha_{\mathrm{m}} \frac{k_{\mathrm{m}}}{k_{\mathrm{f}}} L_{\mathrm{ref}}^{2} \\
& \lambda=\frac{15 k_{\mathrm{m}} L_{\mathrm{ref}}^{2}}{k_{\mathrm{f}} r_{\mathrm{ms}}^{2}}
\end{aligned}
$$

Dimensionless outboundary radius

Dimensionless asymmetry factor

Dimensionless off-left distance

Dimensionless fracture conductivity

Dimensionless surface rate

Dimensionless fracture length

$$
\begin{aligned}
& R_{e D}=\frac{R_{e}}{L_{\text {ref }}} \\
& x_{\text {asymD }}=\frac{x_{\text {assm }}}{L_{\text {ref }}} \\
& r_{\mathrm{OD}}=\frac{r_{0}}{L_{\text {ref }}} \\
& C_{\mathrm{FD}}=\frac{k_{\mathrm{F} F} W_{\mathrm{F}}}{k_{\mathrm{f}} L_{\text {ref }}} \\
& \tilde{q}_{\mathrm{D}}=\frac{\tilde{q} L_{\text {ref }}}{q_{\mathrm{sc}}} \\
& L_{\mathrm{FD}}=\frac{L_{\mathrm{F}}}{L_{\text {ref }}}
\end{aligned}
$$

For the convenience of mathematical model solving, the following dimensionless variable definition is given in Table $\mathbf{1}$.

Where: $r$ is the radial distance in $\mathrm{x}$-y plane, $\mathrm{m} ; h$ is reservoirs thickness, $\mathrm{m} ; T_{\mathrm{sc}}$ is temperature under standard conditions, $K ; T$ is reservoirs temperature, $K ; p_{\mathrm{sc}}$ is pressure under standard conditions, $\mathrm{Pa} ; \phi_{\mathrm{m}}$ is matrix porosity, decimal; $\phi_{\mathrm{f}}$ is natural fracture porosity, decimal; $C_{\mathrm{mt}}$ is matrix system compressibility coefficient, $\mathrm{Pa}^{-1} ; C_{\mathrm{ft}}$ is natural fracture system compressibility coefficient, $\mathrm{Pa}^{-1} ; C_{\mathrm{FD}}$ is Dimensionless fracture conductivity, dimensionless; $\mu$ is the CBM viscosity, cp; $\overline{\tilde{q}}$ is the continuous unite length source strength, $\mathrm{m}^{3} / \mathrm{s} ; k_{\mathrm{f}}$ is the permeability of natural fracture system, $\mathrm{m}^{2} ; k_{\mathrm{m}}$ is the permeability of matrix system, $\mathrm{m}^{2} ; k_{\mathrm{F}}$ is the permeability of hydraulic fracture, $\mathrm{m}^{2} ; \theta$ is the angle from linear source to center of reservoirs, degree; $L_{\text {ref }}$ is reference length, $\mathrm{m} ; L_{\mathrm{F}}$ is fracture length, $\mathrm{m} ; \alpha_{\mathrm{m}}$ is matrix shape factor, dimensionless; $R_{\mathrm{e}}$ is closed boundary radius, $\mathrm{m} ; r_{\mathrm{o}}$ is off-center distance, $\mathrm{m} ; x_{\mathrm{asmy}}$ is distance from the center of hydraulic fracture to wellbore, $\mathrm{m} ; \omega$ is the storativity-ratio, dimensionless; $\lambda$ is interporosity coefficient, dimensionless; subscript $\mathrm{D}$ is the dimensionless.

In cylindrical coordinate system $r-\theta-z$, the location of the line source is assumed to be $\left(r^{\prime}, \theta^{\prime}, z^{\prime}\right)$. According to the work of Guo et al. (2016) and Xu et al. (2020), he two-dimension governing equation in the radial cylindrical system (Ozkan, 1994; Deng et al., 2017) is

$$
\begin{aligned}
& \frac{1}{r_{\mathrm{D}}} \frac{\partial}{\partial r_{\mathrm{D}}}\left(r_{\mathrm{D}} \frac{\partial \Delta \bar{\psi}_{\mathrm{f}}}{\partial r_{\mathrm{D}}}\right)+\frac{1}{r_{\mathrm{D}}^{2}} \frac{\partial}{\partial \theta}\left(\frac{\partial \Delta \bar{\psi}_{\mathrm{f}}}{\partial \theta}\right) \\
& \quad+\frac{1}{r_{\mathrm{D}}} \frac{\overline{\tilde{q}} L_{\mathrm{ref}}}{\pi k_{\mathrm{f}} h} \frac{T p_{\mathrm{sc}}}{T_{\mathrm{sc}}} \delta\left(\theta-\theta^{\prime}\right) \delta\left(r_{\mathrm{D}}-r_{\mathrm{D}}^{\prime}\right) \\
& \quad=f(s) \Delta \bar{\psi}_{\mathrm{f}}
\end{aligned}
$$

Where:

$$
f(s)=\left\{\begin{array}{l}
\omega s+\frac{s \beta_{\mathrm{m}} \lambda(1+\sigma)(1-\omega)}{\beta_{\mathrm{m}} \lambda+s(1+\sigma)(1-\omega)}, \text { Transient state } \\
\omega s+\frac{\beta_{\mathrm{m}} \lambda}{5}\left[\sqrt{15 \frac{s(1+\sigma)(1-\omega)}{\beta_{\mathrm{m}} \lambda}} \operatorname{coth}\left(\sqrt{15 \frac{s(1+\sigma)(1-\omega)}{\beta_{\mathrm{m}} \lambda}}\right)-1\right], \text { Pseudo - steady state }
\end{array}\right.
$$

Where: $r$ ' is the distance from linear source to the center of reservoir, $\mathrm{m}$; $\theta^{\prime}$ is the angle from linear source to the center of reservoir, degree; $\beta_{\mathrm{m}}$ is matrix apparent permeability coefficient, dimensionless; $\sigma$ is adsorption gas desorption coefficient, dimensionless.

The general solution of Eq. 3 is (Ozkan, 1994).

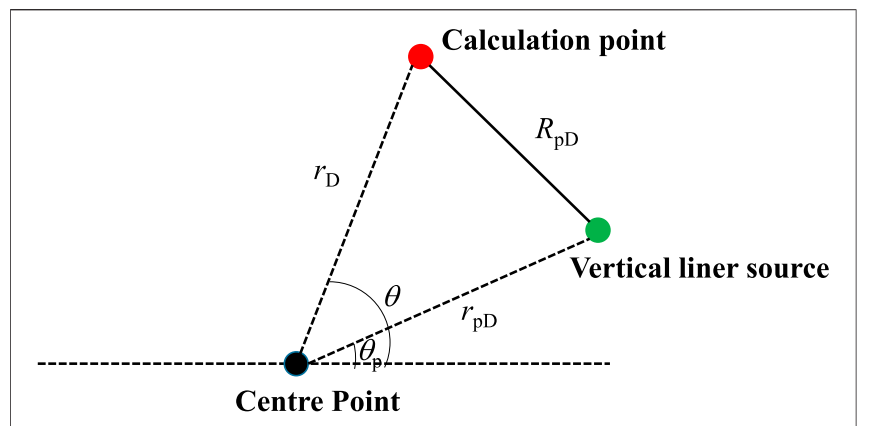

FIGURE 3 | The relationship between calculation point and source.

$$
\Delta \bar{\psi}_{\mathrm{f}}=P+E
$$

Where: $P$ is a center linear source solution of coal gas reservoirs, this solution can be obtained easily. $E$ is chosen such that $P+E$ satisfies the boundary condition at $r=R_{\mathrm{e}}$ and the contribution of $E$ to the flux vanishes as $\theta \rightarrow \theta^{\prime}$ and $r \rightarrow r^{\prime}$.

The position relationship between the calculation point and the vertical line source is shown in Figure 3.

According to the previous research work, the center linear source solution $P$ is (Ozkan and Raghavan, 1991)

$$
P=\frac{\mu \overline{\tilde{q}}}{2 \pi k h_{\mathrm{D}} L_{\mathrm{ref}}}\left[K_{0}\left(R_{\mathrm{pD}} \sqrt{f(s)}\right)+D_{0} I_{0}\left(R_{\mathrm{pD}} \sqrt{f(s)}\right)\right]
$$

Where: $R_{\mathrm{pD}}=\sqrt{r_{\mathrm{D}}^{2}+r_{\mathrm{D}}^{\prime 2}-2 r_{\mathrm{D}} r_{\mathrm{D}}^{\prime} \cos \left(\theta-\theta^{\prime}\right)}$

According to the addition theorem of the Bessel function (Carslaw and Jaeger, 1959)

$$
\begin{aligned}
& I_{k}\left(a R_{\mathrm{pD}}\right)=\sum_{k=-\infty}^{+\infty}(-1)^{k} I_{k}\left(a r_{\mathrm{D}}\right) I_{k}\left(a r_{\mathrm{D}}^{\prime}\right) \cos k\left(\theta-\theta^{\prime}\right) r_{\mathrm{D}}<R_{\mathrm{eD}} \\
& K_{0}\left(a R_{\mathrm{pD}}\right)= \begin{cases}\sum_{k=-\infty}^{+\infty} I_{k}\left(a r_{\mathrm{D}}\right) K_{k}\left(a r_{\mathrm{D}}^{\prime}\right) \cos k\left(\theta-\theta^{\prime}\right) & r_{\mathrm{D}}<r_{\mathrm{D}}^{\prime} \\
\sum_{k=-\infty}^{+\infty} I_{k}\left(a r_{\mathrm{D}}^{\prime}\right) K_{k}\left(a r_{\mathrm{D}}\right) \cos k\left(\theta-\theta^{\prime}\right) & r_{\mathrm{D}} \geq r_{\mathrm{D}}^{\prime}\end{cases}
\end{aligned}
$$

Where: $I_{k}(x)$ is the $k$ order first type Bessel function; $K_{k}(x)$ is the $k$ order second type Bessel function.

Therefore, $E$ can be written as 


$$
E=\frac{\mu \overline{\tilde{q}}}{2 \pi k_{\mathrm{f}} h_{\mathrm{D}} L_{\mathrm{ref}}} 2 \sum_{k=1}^{\infty} D_{k, 0} I_{k}\left(a r_{\mathrm{D}}\right) I_{k}\left(a r_{\mathrm{D}}^{\prime}\right) \cos k\left(\theta-\theta^{\prime}\right)
$$

Finally, when the vertical linear source is not the center of coal gas reservoirs, the general solution can be written as:

$$
\Delta \bar{\psi}_{\mathrm{f}}=\frac{\mu \overline{\tilde{q}}}{2 \pi k h_{\mathrm{D}} L_{\mathrm{ref}}}\left[\begin{array}{c}
K_{0}\left(R_{\mathrm{pD}} \sqrt{f(s)}\right)+D_{0} I_{0}\left(R_{\mathrm{pD}} \sqrt{f(s)}\right)+ \\
2 \sum_{k=1}^{\infty} D_{k} I_{k}\left(a r_{\mathrm{D}}\right) I_{k}\left(a r_{\mathrm{D}}^{\prime}\right) \cos k\left(\theta-\theta^{\prime}\right)
\end{array}\right]
$$

For circle closed boundary.

$$
\left.\frac{\partial \Delta \bar{\psi}_{\mathrm{f}}}{\partial r_{\mathrm{D}}}\right|_{r_{\mathrm{D}}=R_{\mathrm{eD}}}=0
$$

For circle constant-pressure boundary.

$$
\left.\Delta \bar{\psi}_{\mathrm{f}}\right|_{\mathrm{r}_{\mathrm{D}}=\mathrm{R}_{\mathrm{eD}}}=0
$$

Substituting Eq. 9 into Eqs 10, 11, coefficient $D_{\mathrm{k}}(\mathrm{k}=0,1,2, \ldots$ $, \infty)$ can be obtained for circle closed and constant-pressure boundary.

$$
D_{k}=\left\{\begin{array}{l}
-\frac{K_{k}^{\prime}\left(\sqrt{f(s)} R_{e \mathrm{D}}\right)}{I_{k}^{\prime}\left(\sqrt{f(s)} R_{e \mathrm{D}}\right)}, \text { Closed } \\
-\frac{K_{k}\left(\sqrt{f(s)} R_{e \mathrm{D}}\right)}{I_{k}\left(\sqrt{f(s)} R_{e \mathrm{D}}\right)}, \text { Constant pressure }
\end{array} \quad(k=0,1,2, \ldots, \infty)\right.
$$

\section{Off-Center Surface Source Function}

Substituting Eq. 12 into Eq. 9 and using with the dimensionless variable definition in Table 1. The linear source is integrated along the fracture direction and a uniform flux surface source solution can be obtained.

$$
\bar{\psi}_{\mathrm{fD}}=\frac{1}{2} \int_{L_{\mathrm{D}}} \overline{\tilde{q}}_{\mathrm{D}}\left[\begin{array}{c}
K_{0}\left(R_{\mathrm{pD}} \sqrt{f(s)}\right)+D_{0} I_{0}\left(R_{\mathrm{pD}} \sqrt{f(s)}\right)+ \\
2 \sum_{k=1}^{\infty} D_{k} I_{k}\left(a r_{\mathrm{D}}\right) I_{k}\left(a r_{\mathrm{pD}}\right) \cos k\left(\theta-\theta_{\mathrm{p}}\right)
\end{array}\right] d s_{\mathrm{D}}
$$

However, integration of Eq. 13 is very difficult directly. Therefore, according to the triangle similarity and Pythagorean law, there is the following mathematical relationship.

$$
r_{\mathrm{D}}^{\prime}=r_{o \mathrm{D}} \frac{\sin \theta_{\mathrm{F}}}{\sin \left(\theta_{\mathrm{F}}-\theta^{\prime}\right)},\left(\theta_{\mathrm{F}} \neq 0, \pi\right)
$$

Where: $\theta_{\mathrm{F}}$ is the angle between hydraulic fracture and horizontal line, degree.

In order to improve the calculation speed and accuracy, the grid needs to be divided into unequal distances (Figure 4). Dividing the hydraulic fracture into $2 \mathrm{~N}$ segments, and the segment numbers of wellbore left fracture and wellbore right fracture is set as $N$.
The grid end-point coordinates can be expressed as in local coordinate system $\left(r_{\mathrm{F}^{-}} \theta\right)$

$$
r_{\mathrm{FDi}}=\left\{\begin{array}{l}
L_{\mathrm{FRD}} \frac{(N-i+1)}{N},(1 \leq i \leq N+1) \\
L_{\mathrm{FLD}} \frac{(i-N-1)}{N},(N+2 \leq i \leq 2 N+1)
\end{array}\right.
$$

Where: $L_{\mathrm{FRD}}$ is the dimensionless right fracture length; $L_{\mathrm{FLD}}$ is the dimensionless left fracture length; $N$ is the fracture segments number. $r_{\mathrm{FD} i}$ is the $i$-th segment end-point in the local coordinate system.

The grid mid-point coordinates can be expressed as local coordinate system $\left(r_{\mathrm{F}}-\theta\right)$

$$
r_{\mathrm{mFDi}}=\frac{r_{\mathrm{FDi}}+r_{\mathrm{FDi}+1}}{2}(1 \leq i \leq 2 N)
$$

Where: $r_{m \mathrm{FD} i}$ is the $i$-th segment mid-point in the local coordinate system.

The grid end-point coordinates can be expressed as in coordinate system $(r-\theta)$

$$
\left\{\begin{array}{l}
r_{\mathrm{Dj}}=\sqrt{r_{o \mathrm{D}}^{2}+r_{\mathrm{FDi}}^{2}-2 r_{\mathrm{oD}} r_{\mathrm{FDi}} \cos \left(\pi-\theta_{\mathrm{F}}\right)} \\
\theta_{\mathrm{j}}=\tan ^{-1} \frac{r_{\mathrm{FDi}} \sin \theta_{\mathrm{F}}}{r_{\mathrm{oD}}+r_{\mathrm{FDiD}} \cos \theta_{\mathrm{F}}}
\end{array}\right.
$$

The grid mid-point coordinates can be expressed as in coordinate system $(r-\theta)$

$$
\left\{\begin{array}{l}
r_{\mathrm{mDj}}=\sqrt{r_{\mathrm{oD}}^{2}+r_{\mathrm{mFDi}}^{2}-2 r_{\mathrm{oD}} r_{\mathrm{mFDi}} \cos \left(\pi-\theta_{\mathrm{F}}\right)} \\
\theta_{\mathrm{mj}}=\tan ^{-1} \frac{r_{\mathrm{mFDi}} \sin \theta_{\mathrm{F}}}{r_{\mathrm{oD}}+r_{\mathrm{FDiD}} \cos \theta_{\mathrm{F}}}
\end{array}\right.
$$

Where: $r_{m \mathrm{D} i}$ is the $i$-th segment mid-point in $r-\theta$ coordinate system; $r_{\mathrm{D} i}$ is the $i$-th segment end-point in $r-\theta$ coordinate system. $\theta_{m i}$ is the $i$-th segment mid-point degree in $r$ - $\theta$ coordinate system; $\theta_{i}$ is the $i$-th segment end-point degree in $r-\theta$ coordinate system.

However, the pressure drop of the $i$-th segment is.

$$
\begin{aligned}
& \bar{\psi}_{\mathrm{fD}}\left(r_{\mathrm{mDi}}, \theta_{\mathrm{mi}}\right)=\sum_{j=1}^{2 N} \bar{q}_{\mathrm{Dj}} \\
& \int_{\mathrm{r}_{\mathrm{Dj}}}^{r_{\mathrm{Di}+1}} C_{\theta}\left(\begin{array}{l}
K_{0}\left(\varepsilon_{0} \sqrt{\left[r_{\mathrm{mDi}} \cos \left(\theta_{\mathrm{mi}}-\theta^{\prime}\right)-r_{d}^{\prime}\right]^{2}+r_{\mathrm{pD}}^{2} \sin \left(\theta_{\mathrm{mi}}-\theta^{\prime}\right)^{2}}\right)+ \\
D_{0} I_{0}\left(\varepsilon_{0} r_{\mathrm{mDi}}\right) I_{0}\left(\varepsilon_{0} r_{\mathrm{D}}^{\prime}\right)+2 \sum_{k=1}^{+\infty} D_{\mathrm{k}} I_{\mathrm{k}}\left(\varepsilon_{0} r_{\mathrm{mDi}}\right) I_{\mathrm{k}}\left(\varepsilon_{0} r_{\mathrm{D}}^{\prime}\right) \cos k\left(\theta_{\mathrm{mi}}-\theta^{\prime}\right)
\end{array}\right) d r_{D}^{\prime}
\end{aligned}
$$

Where: $C_{\theta}=\frac{r_{\mathrm{oD}} \sin \theta_{\mathrm{F}}}{\sin \left(\theta_{\mathrm{F}}-\theta^{\prime}\right)^{2}} ; \theta^{\prime}=\theta_{\mathrm{F}}-\sin ^{-1} \frac{r_{\mathrm{oD}} \sin \theta_{\mathrm{F}}}{r^{\prime}}$

Wellbore pressure of the off-center vertical fractured well with asymmetric infinite conductivity fracture can be written as.

$$
\bar{\psi}_{\mathrm{fD}}=\sum_{i=1}^{M} \bar{\psi}_{\mathrm{fD}}\left(r_{\mathrm{mDi}}, \theta_{\mathrm{mi}}\right)
$$

Where: $\mathrm{M}$ is the fracture number.

\section{Fracture Flow Model and Coupling}

The fluid flow of fracture is only considered as linear flow. The two wing lengths of hydraulic fracture are unequal. Fracture tips 


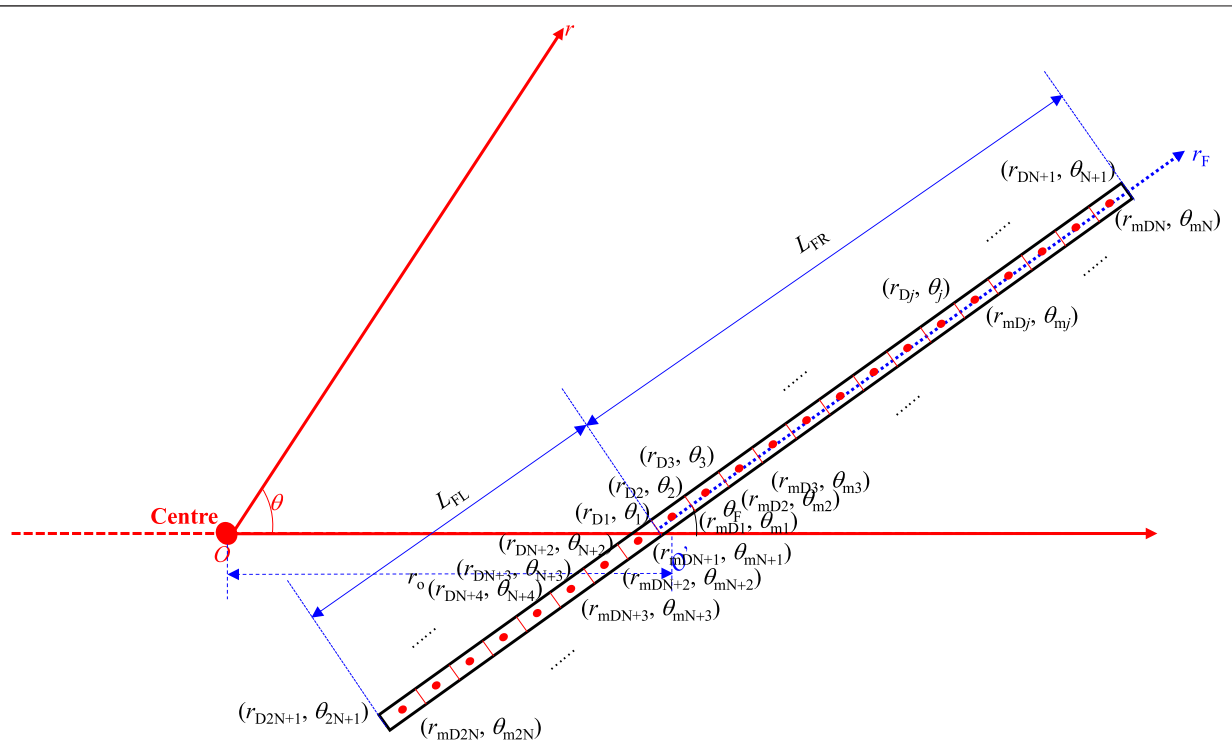

FIGURE 4 | Fracture dispersion diagram.

have no fluid supplement. According to the work of Wang (Wang and Wang, 2014), the solution of hydraulic fracture can be written as:

$$
\begin{gathered}
\bar{\psi}_{\mathrm{fD}}\left(r_{\mathrm{FD}}, s\right)=\bar{\psi}_{\mathrm{fD}, \mathrm{avg}}+\frac{\pi}{C_{\mathrm{FD}}} \int_{-1}^{1} G\left(r^{\prime}, r_{\mathrm{FD}}\right) \overline{\tilde{q}}_{\mathrm{D}}\left(r^{\prime}, \mathrm{s}\right) d r^{\prime} \\
-\frac{2 \pi}{C_{\mathrm{FD}}} G\left(x_{\mathrm{asymD}}, r_{\mathrm{FD}}\right)
\end{gathered}
$$

Where:

$$
\begin{aligned}
G\left(r^{\prime}, r_{\mathrm{FD}}\right) & =\left\{\begin{array}{l}
-\frac{1}{4}\left[\left(r^{\prime}+1\right)^{2}+\left(r_{\mathrm{FD}}-1\right)^{2}-\frac{4}{3}\right]-1 \leq r^{\prime} \leq r_{\mathrm{FD}} \\
-\frac{1}{4}\left[\left(r^{\prime}-1\right)^{2}+\left(r_{\mathrm{FD}}+1\right)^{2}-\frac{4}{3}\right]-1 \leq r^{\prime} \leq r_{\mathrm{FD}}
\end{array} ;\right. \\
\bar{\psi}_{\mathrm{fD}, \mathrm{avg}} & =\frac{1}{2} \int_{-1}^{1} \bar{\psi}_{\mathrm{fD}}\left(r^{\prime}, s\right) d r^{\prime}
\end{aligned}
$$

Where: $\bar{\psi}_{\mathrm{fD}, a v g}$ is the dimensionless average reservoir pressure; $C_{\mathrm{FD}}$ is the dimensionless conductivity. $G(x)$ is the Green function.

The left term of Eq. 21 is the wellbore pressure of infinite conductivity fracture and it can be replaced by Eq. 20. Therefore, the discrete linear equations of Eq. 21 can be written as

$\sum_{j=1}^{2 N} \bar{q}_{\mathrm{Dj}} \int_{r_{\mathrm{D} j}}^{r_{\mathrm{D} j+1}} C_{\theta}\left(\begin{array}{l}K_{0}\left(\varepsilon_{0} \sqrt{\left[r_{\mathrm{mDi}} \cos \left(\theta_{m i}-\theta_{\mathrm{p}}\right)-r_{\mathrm{pD}}\right]^{2}+r_{p D}^{2} \sin \left(\theta_{\mathrm{mi}}-\theta_{p}\right)^{2}}\right)+ \\ D_{0} I_{0}\left(\varepsilon_{0} r_{\mathrm{mD} i}\right) I_{0}\left(\varepsilon_{0} r_{\mathrm{pD}}\right)+2 \sum_{k=1}^{+\infty} D_{\mathrm{k}} I_{\mathrm{k}}\left(\varepsilon_{0} r_{\mathrm{mD} i}\right) I_{\mathrm{k}}\left(\varepsilon_{0} r_{\mathrm{pD}}\right) \cos k\left(\theta_{\mathrm{m} i}-\theta_{\mathrm{p}}\right)\end{array}\right) d r_{\mathrm{pD}}$

$=\bar{\psi}_{\mathrm{fD}, a v g}+\frac{\pi}{C_{\mathrm{FD}}} \sum_{j=1}^{2 N} \int_{r_{\mathrm{FD} j}}^{r_{\mathrm{FD} j+1}} G\left(r^{\prime}, r_{\mathrm{mFD} i}\right) \overline{\tilde{q}}_{\mathrm{D} j}\left(r^{\prime}, s\right)-\frac{2 \pi}{C_{\mathrm{FD}}} G\left(x_{\mathrm{asymD}}, r_{\mathrm{mFDi}}\right) \quad 1 \leq i \leq N$

In addition, according to the mass conservation.

$$
\frac{1}{2} \sum_{j=1}^{2 N} \overline{\tilde{q}}_{\mathrm{D} j}=\frac{1}{s}
$$

Where: $s$ is the Laplace variable.

Combining with Eqs 22, 23, the $2 \mathrm{~N}+1$ linear equation can be obtained and solved by the Gauss elimination method. However, Wellbore pressure still cannot be obtained. Taking surface flux and average pressure into Eq. 21 and letting the $r_{\mathrm{FD}}=x_{\mathrm{asymD}}$, the wellbore pressure of off-center vertical well with asymmetric finite conductivity fracture can be obtained.

Wellbore pressure skin effect and wellbore storage are calculated by Eq. 24 (Van Everdingen and Hurst, 1949).

$$
\bar{\psi}_{\mathrm{wD}}=\frac{s \bar{\psi}_{\mathrm{fD}}+S}{s+C_{\mathrm{D}} s^{2}\left(s \bar{\psi}_{\mathrm{fD}}+S\right)}
$$

Where: $C_{\mathrm{D}}$ is dimensionless well storage; $S$ is the skin, $\bar{\psi}_{\mathrm{wD}}$ is the dimensionless wellbore pressure.

\section{MODEL VERIFICATION}

The model of this paper can be verified by comparing it with a numerical solution. If $x_{\mathrm{asymD}}=0, \sigma=0$ and $\beta_{\mathrm{m}}=1$, our model can be simplified as an off-center fractured well with a finite symmetrical fracture in conventional reservoirs. The model verification basic parameter of this paper and numerical model is shown in Table 2. The Saphir numerical physical model is shown in Figure 5. Basied on the same parameter, the wellbore can be obtained by this paper, and by Saphir, and the comparison figure is shown in Figure 6.

Points on Figure 6 represent the numerical results by the Saphir, the solid line represents the results of the semianalytical solution of this paper. It can be seen from Figure 6 that the numerical solution and the semianalytical solution are matched well. According to the pressure derivative curve, the six flow regimes are 
TABLE 2 | Model verification basic parameter.

\begin{tabular}{|c|c|c|c|}
\hline Parameter & Value & Parameter & Value \\
\hline Storativity ratio & 1 & Formation volume factor & 0.01 \\
\hline Reservoirs thickness & $10 \mathrm{~m}$ & Formation permeability & $0.1 \mathrm{mD}$ \\
\hline Initial reservoirs pressure & $35 \mathrm{MPa}$ & Gas reservoirs temperature & $100^{\circ} \mathrm{C}$ \\
\hline Total compressibility & $0.001 \mathrm{MPa}^{-1}$ & Fracture half-length & $60 \mathrm{~m}$ \\
\hline Reservoirs porosity & 0.05 & Fracture conductivity & $44208 \mathrm{mD} \cdot \mathrm{m}$ \\
\hline Hydraulic fracture angle & $45^{\circ}$ & Distance from wellbore to coal reservoir center & $500 \mathrm{~m}$ \\
\hline Circle closed boundary radius & $1000 \mathrm{~m}$ & & \\
\hline
\end{tabular}

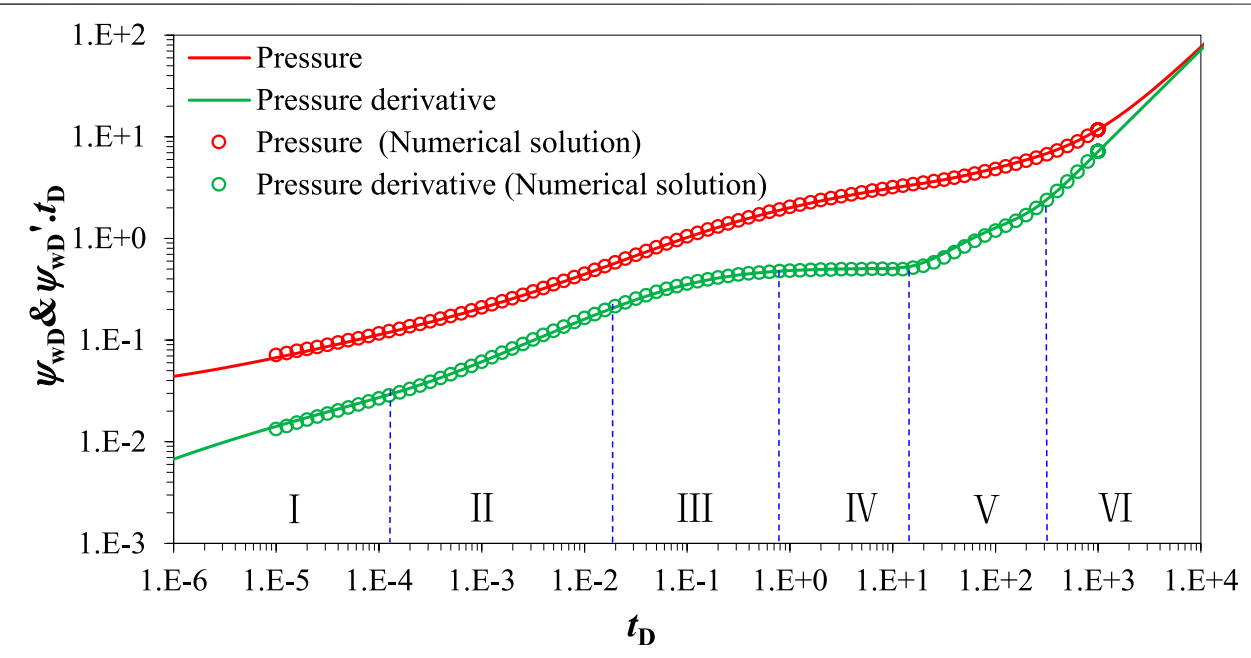

FIGURE 5 | Wellbore pressure comparison curves.

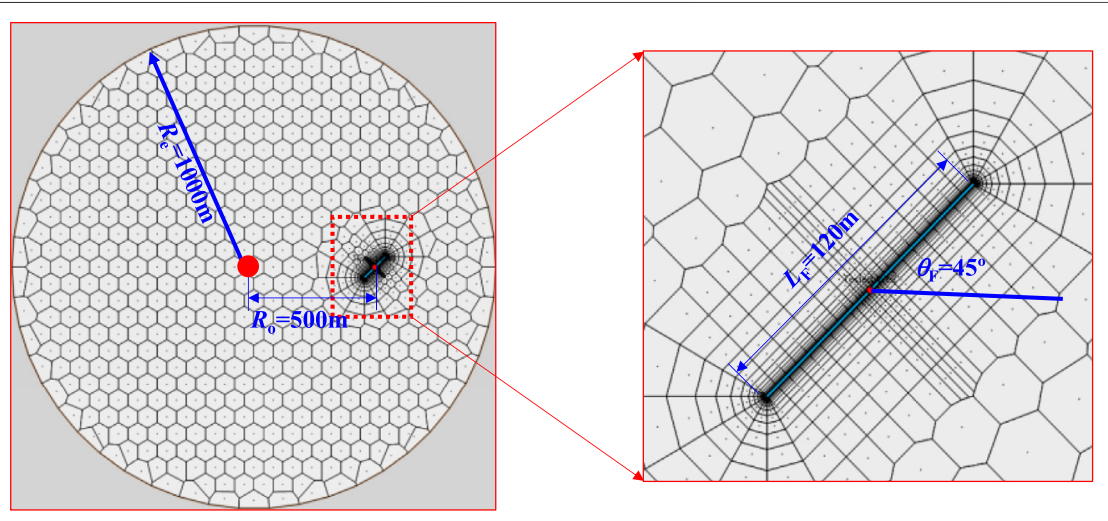

FIGURE 6 | Numerical physical model of the off-center fractured well.

distinguished. The pressure derivative curve characteristic of every flow regime is shown in Table 3.

\section{PARAMETER SENSITIVITY ANALYSIS}

According to the file data analysis result, the basic parameter is given under every figure. Based on these basic parameters, we can analyze the influence of every parameter on wellbore pressure and rate distribution.

\section{Conductivity}

Figure 7 displays the wellbore pressure curve is affected by dimensionless conductivity. The dimensionless conductivity has an obvious influence on wellbore pressure during the linear and bilinear regimes. Large dimensionless conductivity 
TABLE 3 | Flowing regime and characteristic of derivative curve.

\section{Flow regime}

Regime I

Bilinear flow regime: This flow regime mainly reflects the superposition of the linear flow from reservoirs to hydraulic and the linear flow in hydraulic fracture. The characteristic of the derivative curve is a 0.25 -slope straight line

Cinco-Ley et al. (1978)

Regime II

Linear flow regime: This flow regime mainly reflects the superposition of the linear flow from reservoirs to hydraulic. The characteristic of the derivative curve is a 0.5-slope straight line Cinco-Ley et al. (1978)

Regime III

Elliptical flow regime: Since the length of hydraulic fracture is longer than the width of hydraulic fracture, the CBM flow to fractured well by elliptical approach. The characteristic of the derivative curve is a 0.36-slope straight line. It is noted that the elliptical flow regime is not obvious for the actual situation

\section{Sketch map}
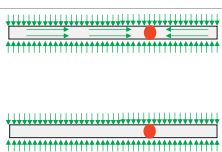

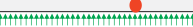

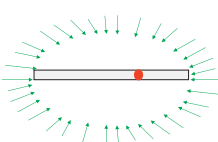

Regime IV

Radial flow regime: As the pressure wave continues to spread, the CBM flow fractured well by radial approach. The characteristic of the derivative curve is a 0.5 -horizontal line

Regime V

Arc boundary reflection regime: When pressure wave spread to closed circle boundary, the arc boundary reflection regime appears and the characteristic of the derivative curve is an "up-warping" curve

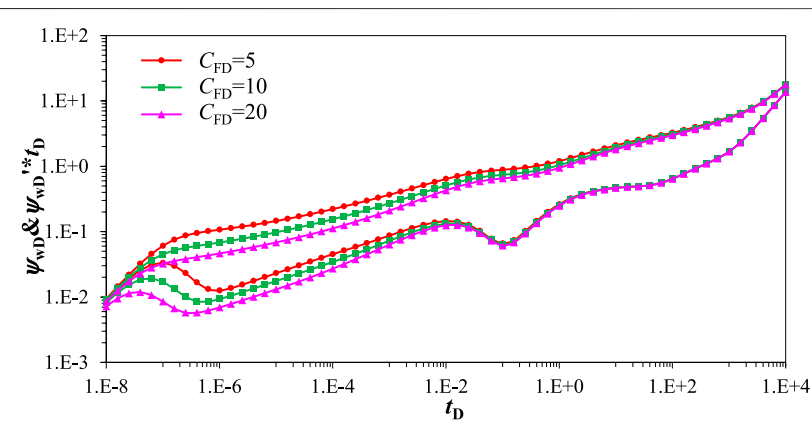

FIGURE 7 | Pressure transient response curve effected by dimensionless conductivity. $\left(C_{\mathrm{D}}=1 \mathrm{e}-5, S=0.01, x_{\mathrm{asymD}}=0.3, L_{\mathrm{F}}=150 \mathrm{~m}, \theta_{\mathrm{F}}=90^{\circ}, R_{\mathrm{e}}=\right.$ $\left.3000 \mathrm{~m}, r_{\mathrm{o}}=2000 \mathrm{~m}, \omega=0.1, \lambda=1, \sigma=0.7, \beta_{\mathrm{m}}=3\right)$.

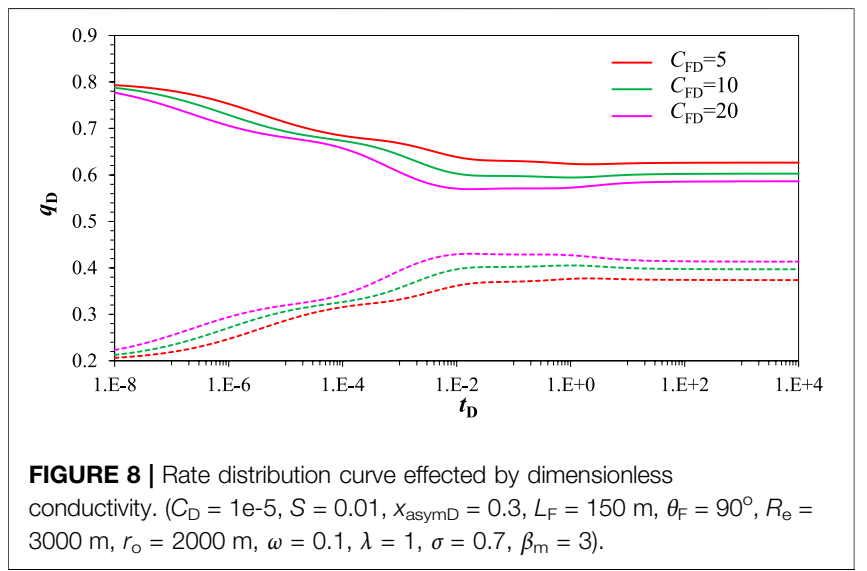

rate contribution of short fracture wing decreases and rate contribution of long fracture wing increases with time increasing before linear flow regime. Rate contribution of short and long fracture wing keep an approximate constant. Therefore, the large dimensionless conductivity leads to a small rate of short fracture wing and a large of long fracture wing in the whole flow regime.

\section{Off-Center Distance}

Figure 9 displays the wellbore pressure curve is affected by the offcenter distance. As is shown in Figure 9, the off-center distance has an obvious effect on wellbore pressure during the arc boundary reflection regime. The larger off-center distance indicates that the well is closed to the circle closed boundary. Pressure waves propagate quickly to the boundary and boundary reaction characteristics appear in advance, which leads to the obvious "upwarping" characteristic of the derivative curve. Therefore, the larger the off-center distance is, 


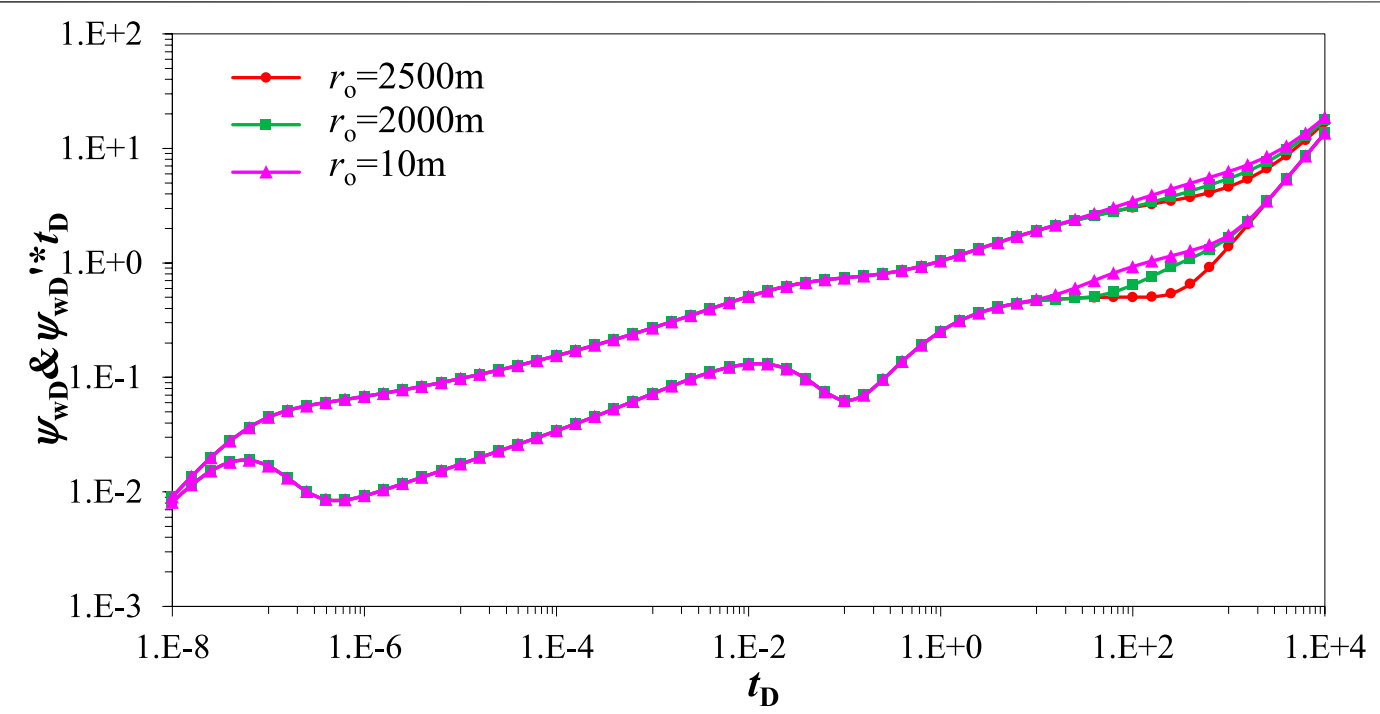

FIGURE 9 Pressure transient response curve effected by the off-center distance. $\left(C_{\mathrm{D}}=1 \mathrm{e}-5, S=0.01, x_{\mathrm{asymD}}=0.3, L_{\mathrm{F}}=150 \mathrm{~m}, \theta_{\mathrm{F}}=90^{\circ}, C_{\mathrm{FD}}=10, R_{\mathrm{e}}=3000 \mathrm{~m}\right.$, $\left.\omega=0.1, \lambda=1, \sigma=0.7, \beta_{\mathrm{m}}=3\right)$.

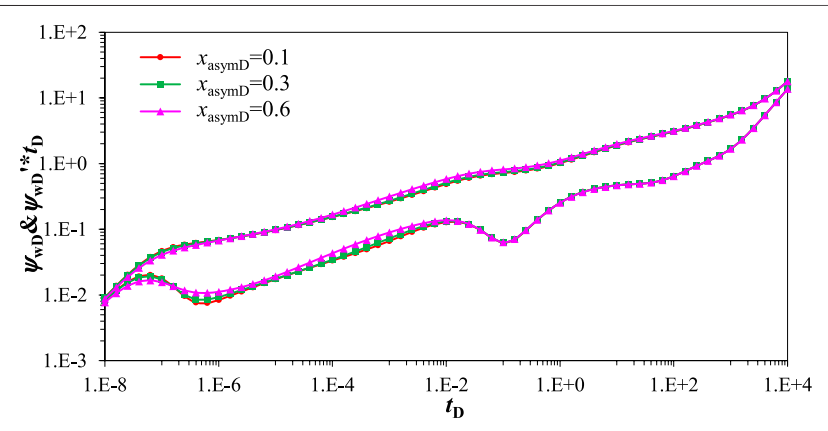

FIGURE 10 | Pressure transient response curve effected by asymmetry factor. $\left(C_{\mathrm{D}}=1 \mathrm{e}-5, S=0.01, L_{\mathrm{F}}=150 \mathrm{~m}, \theta_{\mathrm{F}}=90^{\circ}, C_{\mathrm{FD}}=10, R_{\mathrm{e}}=3000 \mathrm{~m}, r_{\mathrm{O}}=\right.$ $\left.2000 \mathrm{~m}, \omega=0.1, \lambda=1, \sigma=0.7, \beta_{\mathrm{m}}=3\right)$.

the earlier the time of the arc boundary reflection regime and derivative curve "upwarping" is.

\section{Asymmetry Factor}

Figure 10 displays that the wellbore pressure curve is affected by the asymmetry factor. The asymmetry factor has an obvious effect on wellbore pressure during bilinear and linear flow regimes. It is assumed that the fracture length is equal for different asymmetry factors. The larger asymmetry factor indicates that the wellbore is closed to the fracture end-point, which leads that the fluid flows time longer in the long fracture. Therefore, the larger asymmetry factor leads to the larger seepage resistance. That is to say, the larger the asymmetry factor is, the higher of pressure and derivative curve before the radial flow regime is.

Figure 11 displays how the rate distribution curve is affected by the asymmetry factor. The solid line represents the rate distribution of the short fracture and the dots lines represent the rate distribution of the long fracture. The asymmetry factor has an obvious influence on

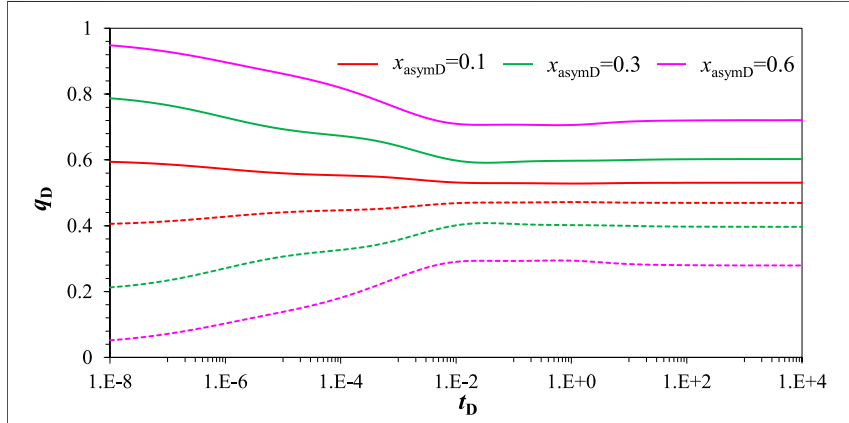

FIGURE 11 | Rate distribution curve effected by asymmetry factor. $\left(C_{\mathrm{D}}=\right.$ $1 \mathrm{e}-5, S=0.01, L_{\mathrm{F}}=150 \mathrm{~m}, \theta_{\mathrm{F}}=90^{\circ}, C_{\mathrm{FD}}=10, R_{\mathrm{e}}=3000 \mathrm{~m}, r_{\mathrm{o}}=2000 \mathrm{~m}, \omega=$ $0.1, \lambda=1, \sigma=0.7, \beta_{\mathrm{m}}=3$.

rate distribution. Since hydraulic fracture is asymmetric about wellbore, pressure wave around the short fracture wing spread to reservoir quickly, so rate contribution of short fracture wing is higher than that of length fracture wing during while flow regime. However, as time progresses, since the control radius of the short fracture wing is smaller than that of the long fracture wing, the rate contribution of the short fracture wing decreases and the rate contribution of the long fracture wing increase with time increasing before linear flow regime. For shorter fracture wing, the larger asymmetry factor leads to a larger pressure drop between the wellbore and hydraulic fracture surface. Therefore, the larger asymmetry factor indicates a larger rate contribution of the short wing. On the contrary, the larger asymmetry factor indicates a larger rate contribution of the short wing with consideration of rate conservation.

\section{Crossflow Model and Storativity Ratio}

Figure 12 displays that the wellbore pressure curve is influenced by different crossflow models. As is shown in Figure 12, a 


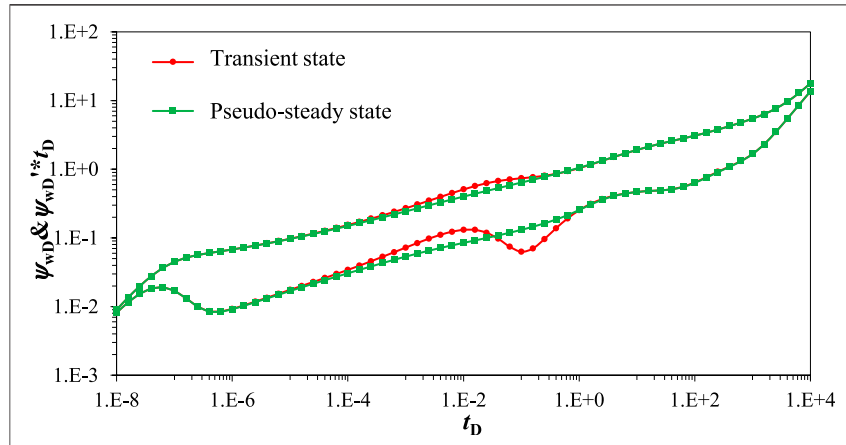

FIGURE 12 | Pressure transient response curve affected by different crossflow model. $\left(C_{\mathrm{D}}=1 \mathrm{e}-5, S=0.01, x_{\mathrm{asymD}}=0.3, L_{\mathrm{F}}=150 \mathrm{~m}, \theta_{\mathrm{F}}=90^{\circ}\right.$, $C_{\mathrm{FD}}=10, R_{\mathrm{e}}=3000 \mathrm{~m}, r_{\mathrm{o}}=2000 \mathrm{~m}, \omega=0.1, \lambda=1, \sigma=0.7, \beta_{\mathrm{m}}=3$ ).

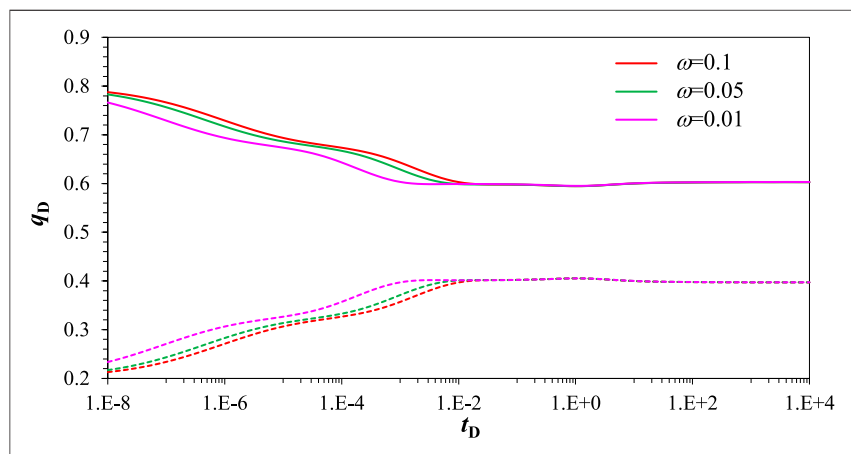

FIGURE 13 $\mid$ Rate distribution curve effected by storativity ratio. $\left(C_{D}=1 \mathrm{e}-\right.$ $5, S=0.01, x_{\text {asymD }}=0.3, L_{\mathrm{F}}=150 \mathrm{~m}, \theta_{\mathrm{F}}=90^{\circ}, C_{\mathrm{FD}}=10, R_{\mathrm{e}}=3000 \mathrm{~m}, r_{\mathrm{O}}=$ $\left.2000 \mathrm{~m}, \lambda=1, \sigma=0.7, \beta_{\mathrm{m}}=3\right)$.

different crossflow model has an obvious influence on wellbore pressure during the crossflow regime. Transient state crossflow shows that the CBM of matrix system can crossflow into naturally fracture system quickly when the pressure of the natural fracture system decreases. On the contrary, pseudo-steady state crossflow shows that the CBM of matrix system cannot crossflow into the natural fracture system quickly when the pressure of the natural fracture system decreases. The CBM of the matrix system can flow out the surface of matrix particles by the seepage type. Therefore, the "concavity" of pressure derivative of transient state crossflow is deeper than that of pseudo-steady state crossflow during crossflow regime.

Figure 13 is the rate distribution curve affected by the storativity ratio. The solid line represents the rate distribution of the short fracture and the dotted lines represent the rate distribution of the long fracture. It is assumed that the crossflow model is transient state crossflow. A large storativity ratio indicates larger storativity volume and a more natural network, which indicates more natural fractures can connect with hydraulic fractures. In addition, since the short fracture wing is closer to the wellbore. the rate contribution of short fracture wing is higher than that of long fracture wing. Therefore, the larger storativity ratio leads to the higher rate contribution of

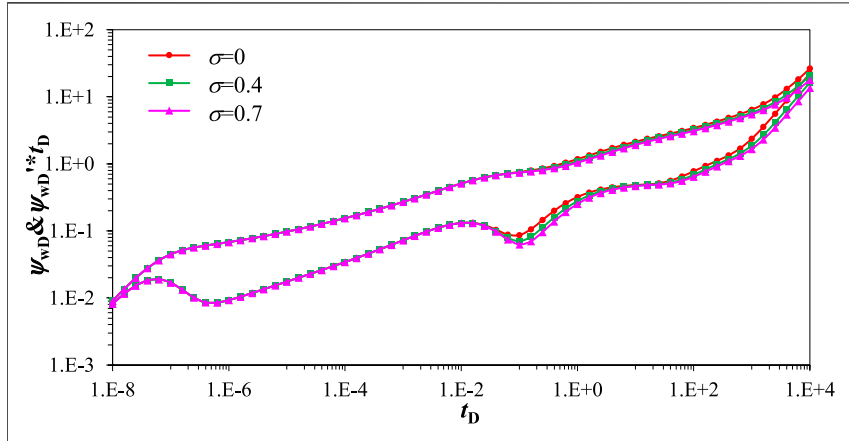

FIGURE 14 | Pressure transient response curve effected by adsorption desorption coefficient. $\left(C_{D}=1 e-5, S=0.01, x_{\text {asymD }}=0.3, L_{F}=150 \mathrm{~m}\right.$, $\left.\theta_{\mathrm{F}}=90^{\circ}, C_{\mathrm{FD}}=10, R_{\mathrm{e}}=3000 \mathrm{~m}, r_{\mathrm{o}}=2000 \mathrm{~m}, \omega=0.1, \lambda=1, \beta_{\mathrm{m}}=3\right)$.

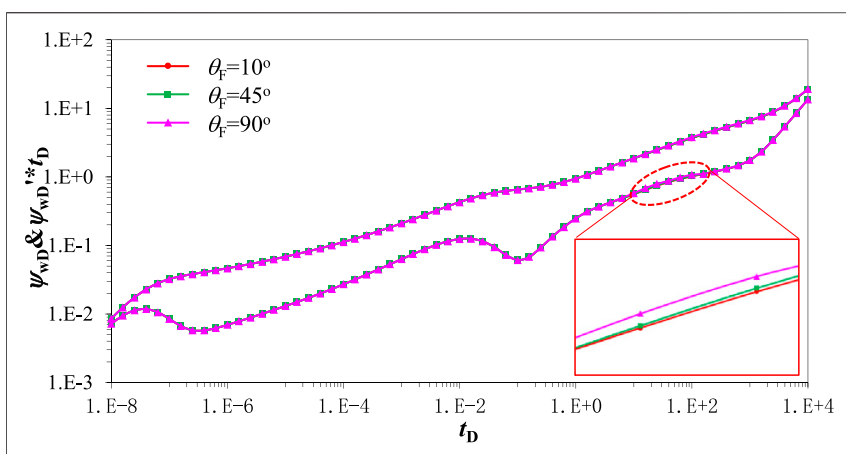

FIGURE 15 | Pressure transient response curve effected by fracture angle. $\left(C_{\mathrm{D}}=1 \mathrm{e}-5, S=0.01, x_{\text {asymD }}=0.3, L_{\mathrm{F}}=150 \mathrm{~m}, C_{\mathrm{FD}}=10, R_{\mathrm{e}}=3000 \mathrm{~m}\right.$, $\left.r_{\mathrm{o}}=2700 \mathrm{~m}, \omega=0.1, \lambda=1, \sigma=0.7, \beta_{\mathrm{m}}=3\right)$.

short fracture wing and small rate contribution of long fracture wing before crossflow regime.

\section{Adsorption Desorption Coefficient}

Figure $\mathbf{1 4}$ is the pressure transient response curve affected by adsorption-desorption coefficient. The adsorption-desorption coefficient mainly affects the typical curve shape after the crossflow regime. The smaller the value of adsorptiondesorption coefficient is, the narrower and shallower the "concave" on the pressure derivative curve is. On the contrary, the larger the value of the adsorption-desorption coefficient is, the wider and deeper the "concave" on the pressure derivative curve is. The larger the amount of adsorbed gas in the coal matrix is, the more obvious the characteristics of crossflow after desorption are.

\section{Fracture Angle}

Figure 15 is a pressure transient response curve influenced by fracture angle. The influence of fracture angle on the pressure derivative curve is not very obvious. The fracture angle physical model is shown in Figure 16. The blue is the hydraulic and the red circle is the wellbore. Since fluid cannot flow into the hydraulic fracture and the largest rate supplement of the hydraulic fracture comes from fracture surface, the pressure 


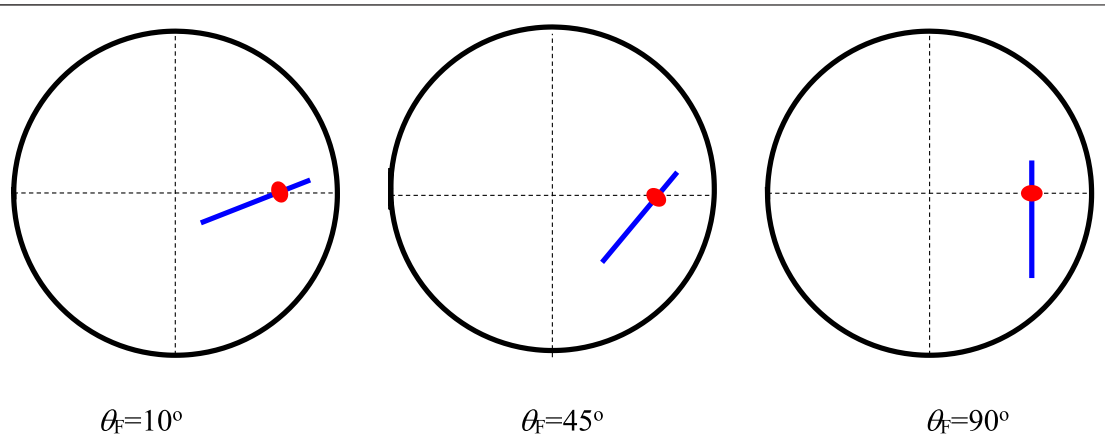

FIGURE 16 | Fracture angle physical model.

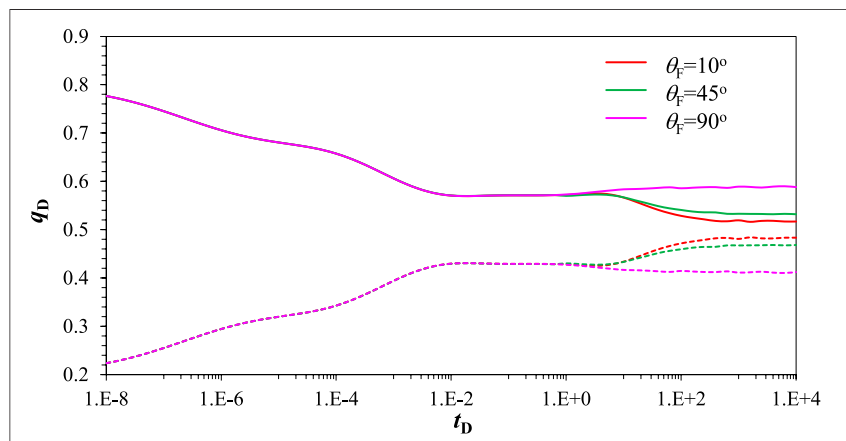

FIGURE 17 | Rate distribution curve affected by fracture angle.

wave can spread to closed boundary quickly with the increasing of the hydraulic fracture angle. Therefore, a larger fracture angle leads to higher pressure derivative curve during the arc boundary reflection regime. However, since the off-center distance is very large, the influence of a larger fracture angle on the pressure derivative curve is not very obvious.

Figure $\mathbf{1 7}$ is the rate distribution curve affected by fracture angle. The solid line represents the rate distribution of the short fracture and the doted lines represent the rate distribution of the long fracture. The fracture angle physical model is shown in Figure 16. The fracture angle has no influence on rate distribution curve before the arc boundary reflection regime. Rate supply around the boundary is finite, so short fracture wing rate contribution decrease with the decreasing of the fracture angle during the arc boundary reflection regime.

\section{FIELD DATA ANALYSIS}

The field data is used to verify and apply the research results of this paper. The basic parameters are as follows: the wellbore radius is $0.1397 \mathrm{~m}$, the height of the reservoir is $5 \mathrm{~m}$, reservoir porosity is 0.103 , the average gas rate is $5500 \mathrm{~m}^{3} / \mathrm{d}$, the CBM viscosity is $1.82 \times$ $10^{-2} \mathrm{mPa}$ s, relative density is 0.568 , volume factor is $5.568 \times 10^{-3}$, compressibility coefficient is $4.138 \times 10^{-2} \mathrm{MPa}^{-1}$, compressibility coefficient of rock is $4.138 \times 10^{-4} \mathrm{MPa}^{-1}$, the total compressibility coefficient is $4.388 \times 10^{-2} \mathrm{MPa}^{-1}$.

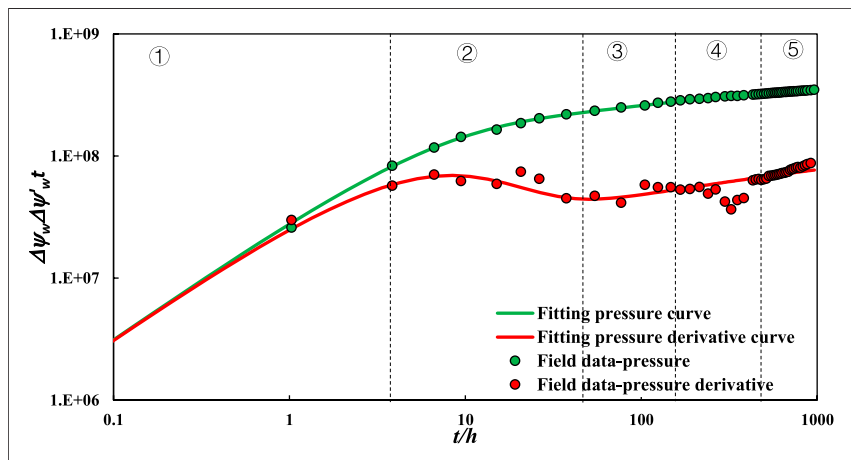

FIGURE 18 | Log-log fitting curve.

According to the pressure derivative curve, the five flow regimes can be diagnosed, which include well storage regime (1), skin reflection region (2), radial flow regime (3), crossflow regime (4), and arc boundary reflection regime (5). However, since well storage is very large, the bilinear and linear flow regimes are covered up. The fitting is shown in Figure 18. The fitting permeability is $25.3 \mathrm{mD}$, well storage is $0.08 \mathrm{~m}^{3} /$ $\mathrm{MPa}$, the storativity-ratio is 0.186 , and the interporosity coefficient is $1.25 \times 10^{-7}$. Matrix apparent permeability coefficient is 1.2, dimensionless; adsorption gas desorption coefficient is 0.4 . Off-center distance is $3610 \mathrm{~m}$ and the control radius of a single well is $3,726.4 \mathrm{~m}$. Distance from the center of hydraulic fracture to the wellbore is $40 \mathrm{~m}$, and the half-length of hydraulic fracture is $78 \mathrm{~m}$.

\section{CONCLUSION}

Based on the micro seepage mechanism of the CBM, the semianalytical model of off-center fractured well with asymmetric finite conductivity fracture. According to the pressure derivative curve characteristic and parameter sensitivity analysis, the following main conclusion can be drawn in this paper.

1) This semi-analytical solution is verified with a numerical solution and the calculation speed of our semi-analytical model is greater than numerical simulation. 
2) Compared to center fractured well, our semi-analytical model has the ability to identify six flow regimes, which include bilinear flow, linear flow, elliptic flow, radial flow, arc boundary reflection, and boundary dominated flow regimes.

3) Off-center distance and fracture angle have an influence on the starting-time of arc boundary reflection. Compared to fracture angle, off-center distance has a sensitive influence on the pressure derivative curve of the arc boundary reflection regime. The larger off-center distance and fracture angle lead to a larger pressure derivative curve during the arc boundary reflection regime.

4) Fracture conductivity, asymmetry factor has obvious influence on the early flow regime. As the fracture conductivity increases, the asymmetry factor decreases, pressure, and the derivative curve is smaller during bilinear flow and linear flow regime.

5) Our application also evaluates hydraulic fracturing result and provide guidance to diagnose well location to the closed boundary.

\section{DATA AVAILABILITY STATEMENT}

The original contributions presented in the study are included in the article/Supplementary Material, further inquiries can be directed to the corresponding author.

\section{REFERENCES}

Aminian, K., and Ameri, S. (2009). Predicting Production Performance of Cbm Reservoirs. J. Nat. Gas Sci. Eng. 1 (1), 25-30. doi:10.1016/j.jngse.2009.03.003

Bennett, C. O., Rosato, N. D., and Reynolds, A. C. (1983). Influence of Fracture Heterogeneity and wing Length on the Response of Vertically Fractured wells. SPE-98-PAJ Soc. Pet. Eng. J. 23 (02), 219-230. doi:10.2118/9886-PA

Berumen, S., Tiab, D., and Rodriguez, F. (2000). Constant Rate Solutions for a Fractured Well with an Asymmetric Fracture. J. Pet. Sci. Eng. 25 (1), 49-58. doi:10.1016/S0920-4105(99)00053-4

Carslaw, H. S., and Jaeger, J. C. (1959). Conduction of Heat in Solids. second edition. London: Oxford University Press.

Chen, Z., Liao, X., Zhao, X., Dou, X., and Zhu, L. (2016). A Semi-analytical Mathematical Model for Transient Pressure Behavior of Multiple Fractured Vertical Well in Coal Reservoirs Incorporating with Diffusion, Adsorption, and Stress-Sensitivity. J. Nat. Gas Sci. Eng. 29, 570-582. doi:10.1016/j.jngse.2015. 08.043

Cinco L., H. H., Samaniego V., F. F., and Dominguez A., N. (1978). Transient Pressure Behavior for a Well with a Finite-Conductivity Vertical Fracture. SPE98-PA 18 (04), 253-264. doi:10.2118/6014-PA

Cinco-Ley, H., and Meng, H.-Z. (1988). Pressure Transient Analysis of wells with Finite Conductivity Vertical Fractures in Double Porosity Reservoirs. Houston, Texas: Paper presented at the SPE Annual Technical Conference and Exhibition. doi:10.2118/18172-MSPressure Transient Analysis of Wells with Finite Conductivity Vertical Fractures in Double Porosity Reservoirs

Crawford, P. B., and Landrum, B. L. (1955). Effect of Unsymmetrical Vertical Fractures on Production Capacity. Trans. AIME 204 (01), 251-254. doi:10. 2118/433-G

Deng, Q., Nie, R.-S., Jia, Y.-L., Guo, Q., Jiang, K.-J., Chen, X., et al. (2017). Pressure Transient Behavior of a Fractured Well in Multi-Region Composite Reservoirs. J. Pet. Sci. Eng. 158, 535-553. doi:10.1016/j.petrol.2017.08.079

Guo, J., Wang, H., and Zhang, L. 2016. Transient Pressure and Production Dynamics of Multi-Stage Fractured Horizontal wells in Shale Gas Reservoirs with Stimulated Reservoir Volume. J. Nat. Gas Sci. Eng., 35: 425-443. doi:10. 1016/j.jngse.2016.08.074

\section{AUTHOR CONTRIBUTIONS}

AJ: Writing-original draft, conceptualization, code, methodology, model validation. ZC: Writing- review and editing, participated the discussions YW: Participated the discussions GZ: Data curation, supervision, constructive discussions guidance $\mathrm{ZM}$ : Figure description, supervision, model validation FC: Field application.

\section{FUNDING}

This article was supported by the Natural Science Foundation of Gansu Province (21JR1RM327), Innovation Foundation of Colleges and Universities in Gansu Province (2021A-127), and National Natural Science Foundation of China Regional Science Foundation Project (42162015).

\section{SUPPLEMENTARY MATERIAL}

The Supplementary Material for this article can be found online at: https://www.frontiersin.org/articles/10.3389/fenrg.2022.829914/ full\#supplementary-material

Huang, T., Guo, X., and Chen, F. (2015). Modeling Transient Pressure Behavior of a Fractured Well for Shale Gas Reservoirs Based on the Properties of Nanopores. J. Nat. Gas Sci. Eng. 23, 387-398. doi:10.1016/j.jngse.2015.02.020 Langmuir, I. (1917). The Constitution and Fundamental Properties of Solids and Liquids. Part II.-Liquids. J. Franklin Inst. 184 (5), 721. doi:10.1016/S0016-0032(17)90088-2

Lei, W., Xiao-dong, W., Xu-min, D., Li, Z., and Chen, L. (2012). Rate Decline Curves Analysis of a Vertical Fractured Well with Fracture Face Damage. J. Energ. Resour. Technology-Transactions Asme 134 (3). doi:10.1115/1.4006865

Liu, Y., Xu, H., Tang, D., Xu, F., Mathews, J. P., Hou, W., et al. (2020). Coalbed Methane Production of a Heterogeneous Reservoir in the Ordos basin, china. J. Nat. Gas Sci. Eng. 82, 103502. doi:10.1016/j.jngse.2020.103502

Narasimhan, T. N., and Palen, W. A. (1979). A Purely Numerical Approach for Analyzing Fluid Flow to a Well Intercepting a Vertical Fracture. Paper presented at the. California: SPE California Regional Meeting.

Nie, R.-S., Meng, Y.-F., Guo, J.-C., and Jia, Y.-L. (2012). Modeling Transient Flow Behavior of a Horizontal Well in a Coal Seam. Int. J. Coal Geology. 92, 54-68. doi:10.1016/j.coal.2011.12.005

Ozkan, E. (1994). New Solutions for Well-Test-Analysis Problems: Part IiiAdditional Algorithms. Paper presented SPE Annu. Tech. Conf. Exhibition. doi:10.2118/28424-ms

Ozkan, E., and Raghavan, R. 1991. New Solutions for Well-Test-Analysis Problems: Part 1-analytical Considerations(includes Associated Papers 28666 and 29213 ). SPE Formation Eval., 6(3): 359-368. doi:10.2118/18615-PA

Peaceman, D. W. (1990). Interpretation of Wellblock Pressures in Numerical Reservoir Simulation: Part 3 -- off-center and Multiple wells within a wellblockSPE Reservoir Engineering. SPE Reservoir Eng. 5 (02), 227-232. doi:10.2118/16976-PA

Pillalamarry, M., Harpalani, S., and Liu, S. (2011). Gas Diffusion Behavior of Coal and its Impact on Production from Coalbed Methane Reservoirs. Int. J. Coal Geology. 86 (4), 342-348. doi:10.1016/j.coal.2011.03.007

Rodriguez, F., Cinco-Ley, H., and Samaniego, -V., F. (1992). Evaluation of Fracture Asymmetry of Finite-Conductivity Fractured wellsSPE Production Engineering. SPE Prod. Eng. 7 (02), 233-239. doi:10.2118/20583-PA

Rosa, A. J., Magalhaes, A. A. C., and Horne, R. N. (1996). Pressure Transient Behavior in Reservoirs with an Internal Circular Discontinuity. SPE J. 1 (01), 83-92. doi:10.2118/26455-PA 
Tiab, D., Lu, J., Nguyen, H., and Owayed, J. (2010). Evaluation of Fracture Asymmetry of Finite-Conductivity Fractured wells. J. Energ. Resour. Tech. 132 (1). doi:10.1115/1.4000700

Van Everdingen, A. F., and Hurst, W. (1949). The Application of the Laplace Transformation to Flow Problems in Reservoirs. J. Pet. Tech. 1 (12), 305-324. doi:10.2118/949305-G

Wang, H., Kou, Z., Guo, J., and Chen, Z. (2021). A Semi-analytical Model for the Transient Pressure Behaviors of a Multiple Fractured Well in a Coal Seam Gas Reservoir. J. Pet. Sci. Eng. 198, 108159. doi:10.1016/j.petrol.2020.108159

Wang, L., Dai, C., Li, X., Chen, X., and Xia, Z. (2019). Pressure Transient Analysis for Asymmetrically Fractured wells in Dual-Permeability Organic Compound Reservoir of Hydrogen and Carbon. Int. J. Hydrogen Energ. 44 (11), 5254-5261. doi:10.1016/j.ijhydene.2018.08.082

Wang, L., Wang, X., Li, J., and Wang, J. (2013). Simulation of Pressure Transient Behavior for Asymmetrically Finite-Conductivity Fractured wells in Coal Reservoirs. Transp Porous Med. 97 (3), 353-372. doi:10.1007/s11242-0130128-z

Wang, L., and Wang, X. (2014). Type Curves Analysis for Asymmetrically Fractured wells. J. Energ. Resour. Technology-Transactions Asme 136 (2). doi:10.1115/1.4025712

Wang, L., and Xue, L. (2018). A Laplace-Transform Boundary Element Model for Pumping Tests in Irregularly Shaped Double-Porosity Aquifers. J. Hydrol. 567, 712-720. doi:10.1016/j.jhydrol.2018.06.027

Warren, J. E., and Root, P. J. (1963). The Behavior of Naturally Fractured Reservoirs. SPE-98-PA 3 (03), 245-255. doi:10.2118/426-PA

Xu, Y., Li, X., and Liu, Q. (2020). Pressure Performance of Multi-Stage Fractured Horizontal Well with Stimulated Reservoir Volume and Irregular Fractures Distribution in Shale Gas Reservoirs. J. Nat. Gas Sci. Eng. 77, 103209. doi:10. 1016/j.jngse.2020.103209

Zhao, Y.-l., Shan, B.-c., and Zhang, L.-h. (2019). Pressure Dynamics of Asymmetrically Fractured wells in an Arbitrarily Shaped Reservoir. J. Hydrodyn 31 (4), 767-777. doi:10.1007/s42241-018-0166-7
Zhao, Y.-l, Zhang, L.-H., Feng, G.-Q., Zhang, B.-N., and Kang, B. (2016). Performance Analysis of Fractured wells with Stimulated Reservoir Volume in Coal Seam Reservoirs. Oil Gas Sci. Technol. - Rev. IFP Energies Nouvelles 71 (1), 8.

Zhao, Y., Li, H., Zhang, L., and Kang, B. (2017). Pressure Transient Analysis for Off-Centered Fractured Vertical wells in Arbitrarily Shaped Gas Reservoirs with the Bem. J. Pet. Sci. Eng., 156: 167-180. doi:10.1016/j.petrol.2017.05.015

Zuber, M. D., and Kuuskraa, V. A. (1990). Optimizing Well Spacing and Hydraulic-Fracture Design for Economic Recovery of Coalbed methaneFormation Evaluation. SPE Formation Eval. 5 (01), 98-102. doi:10. 2118/17726-PA

Conflict of Interest: Author ZM was employed by the company PetroChina Southwest Oil \& Gasfield Company. Author FC was employed by the company PetroChina Qinghai Oil Field Company.

The remaining authors declare that the research was conducted in the absence of any commercial or financial relationships that could be construed as a potential conflict of interest.

Publisher's Note: All claims expressed in this article are solely those of the authors and do not necessarily represent those of their affiliated organizations, or those of the publisher, the editors, and the reviewers. Any product that may be evaluated in this article, or claim that may be made by its manufacturer, is not guaranteed or endorsed by the publisher.

Copyright (c) 2022 Ji, Chen, Wang, Zhang, Mao and Chen. This is an open-access article distributed under the terms of the Creative Commons Attribution License (CC $B Y)$. The use, distribution or reproduction in other forums is permitted, provided the original author(s) and the copyright owner(s) are credited and that the original publication in this journal is cited, in accordance with accepted academic practice. No use, distribution or reproduction is permitted which does not comply with these terms. 